\title{
Walking the line? An investigation into elite athletes' sport-related use of painkillers and their willingness to use analgesics to train or compete when injured
}

Marie Overbye: marie.overbye@stir.ac.uk

International Review for the Sociology of Sport: https://doi.org/10.1177/1012690220973552

\begin{abstract}
Pain and injuries are inevitable occupational hazards and health risks in athletes' working lives. The sport-related use of analgesics with and without injury is widespread. Taking analgesics to compete while injured is conceptualised as a sickness presenteeism problem. This study examines the complexity of the sport-related use of analgesics in elite sport. A mixed-method design was adopted consisting of a survey $(n=775)$ and interviews $(n=21)$ with elite athletes. Many athletes reported a sport-related use of analgesics. Analgesics had commonly been used to enable an injured athlete to: compete in an important match; train during an important period; qualify for an important match/final; and keep one's position on the team or have one's contract prolonged. In particular, team-sport athletes had experience of such use. Apart from the therapeutic use of analgesics, they were sometimes integrated into different routines: for example, enhancing performance, avoid lowering performance, aiding recovery, training/competing injured and prophylactic use. Simultaneously, many had refrained from using or sought to minimise their sport-related use of analgesics; reasons were related to: trust in/feeling the body, side-effects, knowledge and social norms. Social norms and interaction with support personnel played a key role. Physiotherapists and doctors often advised athletes on analgesics, but self-administered use was widespread. How risk cultures manifested themselves varied greatly between sports, and gender differences were scarce. Although 'absenteeism' is also present, a majority of athletes would be willing to 'walk the line', using analgesics to compete when injuries may threaten their career or sporting success.
\end{abstract}

Keywords: culture of risk, drugs, gender, injury, non-steroidal anti-inflammatory drugs, occupational health, playing hurt, presenteeism, risk acceptance 


\section{Introduction}

Pain and injuries are inevitable occupational hazards and health risks in the working lives of athletes (Beamish and Ritchie, 2006). The prevalence of injuries is high across a range of sports (Ristolainen et al. 2012). Frequent or severe injuries pose a threat to athletes' careers and can affect occupational health and wellbeing: for example, injuries can be associated with a painful rehabilitation process and create uncertainty about the future (Thing, 2006); affect results and ranking (Roosen and Heijne, 2018); lead to early or involuntary termination of a sporting career (Ristolainen et al., 2012); cause a permanent disability (Turner et al., 2000); and harm mental health and wellbeing during a sporting career (Roderick, 2006; Wiese-Bjornstal, 2010) as well as after the career has ended (Gouttebarge et al., 2015).

Concurrently, there is a high prevalence of the sport-related use of analgesics across a range of sports (Alaranta et al., 2006; Tscholl et al., 2015), particularly non-steroidal anti-inflammatory drugs (NSAIDs). Training or competing with injuries often involves the use of analgesic medicines or injections, but the prophylactic use of analgesics is also common (Warden, 2009) in endurance events (Joslin et al., 2013) and team sports (Tscholl et al., 2015). Analgesics are an integral part of pain management in sport (Hainline et al., 2017) as a self-administered therapy and/or under supervision. Increase in pain tolerance due to the use of analgesics may explain a slight effect on endurance performance parameters and aspects of neuromuscular performance (Lundberg and Howatson, 2018). The general effects of analgesics depend on the type, on the dosage and whether poly-drug use is involved. The products cover, for example: nonsteroidal anti-inflammatory effects and pain relief (NSAIDs, e.g. ibuprofen), steroidal anti-inflammatory and metabolic effects and pain relieve (e.g. glucocorticoids), and non- NSAIDs with mild (e.g. paracetamol) to moderate or strong pain relief (opioids, e.g. tramadol).

The prophylactic (Warden, 2009) and therapeutic (Alaranta et al., 2006) use of NSAIDs may lead to acute side-effects (e.g. potentially severe side-effects in the gastrointestinal tract and kidneys). The use of cortisone can have serious short- and long-term side-effects (Vernec et al., 2019). Despite some evidence of the positive effect of NSAID use after acute muscle injury (Morelli et al., 2018) the benefits of NSAID treatment on muscle repair after injury might be outweighed by the costs, i.e. potentially long-term negative effects, for example on muscle recovery (Mackey et al., 2012). 
The use of analgesics has negative impacts on some athletes even after the end of their sporting career. For example, retired athletes' current (mis)use of analgesics has been linked to issues arising during their sporting career, for example the misuse of opioids (Cottler et al., 2011) and the alleviation of pain and inflammation associated with football injuries (Sanders and Stevinson, 2017). Most of the commonly used analgesics are permitted in sport. Tramadol has recently been prohibited in cycling. Sport-related uses of glucocorticoids (cortisone) are widespread (Vernec et al., 2019). Glucocorticoids are prohibited in sport only in competitions by 'systemic' (oral, rectal, intramuscular or intravenous) routes, but per- mitted via local administration (e.g. intra-articular injections) and used as treatment for several conditions, including injuries, and sometimes (mis)used in the absence of a medical condition.

\subsection{Culture of risk and precarious working conditions}

Embedded in elite sports is a normalised 'culture of risk' (Bette, 2004) in which competing hurt, the expectation of always striving for success and accepting health risks are internalised by athletes, coaches and sports medicine specialists (Andersen and Jackson, 2013; Roderick, 2006). Sporting careers are often short-lived, insecure and uncertain (Roderick, 2006) with a significantly higher risk of injury and dependence on the body's functionality compared with most other occupations (Bette, 2004). Thus, injured athletes face time pressures to play hurt or return to sport too quickly. Athletes's strong commitment and striving for success often leads to them playing while injured, which in turn increases the impairment and thus eventually reduces the chance of obtaining sporting success - the 'risk-pain-injury paradox' (Nixon, 1996). A recent study has added a new dimension to these issues when conceptualising the phenomenon of playing hurt as a sport-specific 'sickness presenteeism' problem (Mayer and Thiel, 2018). From this perspective, accepting (or ignoring) health risks and training or competing when injured can be considered as work presenteeism, i.e., working while ill or injured (Johns, 2010; Mayer and Thiel, 2018), and the use of analgesics may become a tool in this endeavour.

In the working context of sport, athletes who do not comply with sickness presenteeism, for example, are unwilling to 'play hurt' (using analgesics) risk being stigmatised, isolated and ignored by managers (Roderick, 2006; Law and Bloyce, 2019). Coaches and medical staff play a pivotal role in decisions whether to compete while injured (Mayer and Thiel, 2018). Medical personnel are faced with dual roles 
and pressures and must negotiate between restoring athletes' health while simultaneously assisting in enhancing performance levels (Andersen and Jackson, 2013; Safai, 2003). This is an interaction that occasionally relates medical advice to lack of care for the injured athlete's health (Waddington and Roderick, 2002), breaches in athlete-patient confidentiality (Malcolm and Scott, 2014) and often results in a too early return to sport and in the use of analgesics to be able to do so (Waddington and Roderick, 2002).

Studies suggest that male and female athletes from different countries internalise the 'culture of risk' to a similar degree (Nixon, 1996; Charlesworth and Young, 2006). Accordingly, several studies report a gender difference neither in the prevalence of the use of NSAIDs (Alaranta et al, 2006; Tscholl et al., 2015) nor in their willingness to compete hurt (Mayer and Thiel, 2018; Mayer et al., 2018).

On the other hand, how the risk culture manifests itself varies greatly between sports disciplines (Mayer and Thiel, 2018; Schnell et al., 2014). Sports disciplines also vary in their injury risk profiles (Hägglund et al., 2016) and in the use of NSAIDs (Alaranta et al., 2006).

\subsection{Sport as an exceptional and risky occupation: the sport-related use of analgesics and} presenteeism

Drawing on Rhodes' (2009) risk environment framework (while integrating concepts from figurational sociology), it has been argued that elite sport constitutes a unique social practice comprising an exceptional and risky working environment in which some unique features - interactions and interdependencies between individuals and environments - foster specific risk environments and occupational risks that differ from other working contexts (Overbye, 2018). Some of these features involve specific working conditions and demands on athletes, some of which concur with risk factors associated with sickness presenteeism (e.g. job insecurity, time pressure, little replaceability, treating the working environment as home and being over-committed to work, Hansen and Andersen, 2008). Specific working conditions and interdependencies help to understand an increased sport-work related use of pain-relieving medicines and how multiple actors impact on both harm production and the reduction of drug use in this regard (Overbye, 2018). Athletes are socialised into the working context of sport and drug use (Ohl et al., 2015), which implies striving for performance enhancement and accepting health risks (Section 1.1). The pivotal role of the body's functionality to do the job becomes the Achilles heel (Bette, 2004). In this context (sickness) presenteeism 
(Johns, 2010; Section 1.1) involving analgesics may become a socially encouraged practice - although absenteeism is also present. Sport-related drug use (including analgesics) is expected and can be understood as coping with the specific working context (Overbye, 2018). Apart from the "normal" therapeutic use of analgesics (e.g. injury treatment or operation), they may be used to cope with career obstacles such as injuries (Tscholl et al., 2015) or selection-related stressors (Didymus and Backhouse, 2020); to enhance performance or avoid lower performance due to pain or small injuries; and also as a prophylactic. Importantly, considering the different definitions of presenteeism (Johns, 2010:521) different types of the sport-related use of analgesics may also constitute forms of presenteeism, for example, involving running health risks to attend work. ${ }^{1}$

\subsection{Aims of the study}

Mayer and Thiel (2018) highlight the significance of not only the structure of the working context but also personal and organisational expectations with regard to absenteeism or presenteeism, thus suggesting that advice on, and the sport-related use of, analgesics varies greatly within sporting contexts and during an athlete's career. Moreover, Dunn (2015) emphasises the importance of understanding the prevalence and the motivations for the use of pain-relieving prescription medicines in sport.

The research field related to sickness presenteeism has been dominated by qualitative studies. Exceptions to this are recent German quantitative studies (Mayer and Thiel, 2018; Mayer et al., 2018; Schnell et al., 2014). Further, knowledge about athletes' use of analgesics to be able to train and compete when injured is scarce. Mayer and Thiel (2018) and Mayer et al. (2018) have integrated one item measuring whether athletes would find it legitimate or would refuse to compete if they had to take painkillers to do so. These studies provide novel insights into sickness presenteeism among German elite handball and track-and-field athletes, and characteristics of elite sport subcultures affecting German adolescent elite athletes' willingness to compete hurt.

Yet we lack knowledge of not only situational aspects such as which situations motivate to use of analgesics in and out-of-competition but also why some athletes - even within cultures of risk, in which analgesics is standard practice - refrain from using painkillers. Knowledge is also scarce concerning the complexity of the sport-related use of analgesics such as for performance enhancement, recovery and 
prophylactic use. No studies have (so far) explored a larger group of elite athletes' approaches to the sportrelated use of analgesics - with and without injuries - and their thoughts on use and guidance applying a mixed-method design. Further, although differences have been identified between sports, we still lack knowledge about sport-specific issues and whether gender specific patterns exist.

To fill this gap, the current study applies a mixed-method design and sets out to investigate the following research questions: firstly, how large is the proportion of Danish elite athletes who have used analgesics in connection with their sport? (RQ1); secondly, why and when have athletes engaged in a sportrelated use of analgesics? And how do different situations and circumstances affect athletes' willingness to use analgesics in sport? (RQ2); thirdly, do athletes seek to refrain from or minimise the use of analgesics? And what are the reasons for refraining from analgesics? (RQ3); fourthly, who supervises athletes' use of analgesics? What role can the sporting/training environment play in the use of analgesics? How do athletes approach guidance and the self-administration of analgesics? (RQ4); And, fifthly, how do athletes of different genders and sports differ in their approaches to analgesics? (RQ5).

\section{Material and methods}

\subsection{Procedure and participants}

A web-based questionnaire was distributed by email to all of the Danish elite athletes supported by the national elite organisation Team Danmark (69.5\%) and to additional national team athletes from sports federations/teams not included in Team Danmark's support programme (30.5\%). A total of 775 athletes completed the questionnaire (response rate: $51 \%$ ), of whom $41 \%$ were female and 59\% male athletes with a mean age of 22 years. A total of 696 athletes answered the survey questions on analgesics. Forty sports were represented and grouped into Team Sports (47\%) and Individual Sports (53\%). Among the athletes supported by Team Danmark 14\% were categorised (by Team Danmark) as "world-class athletes" (ranked eighth or better at the world championship or Olympic Games); $26 \%$ were "elite athletes" (national senior team athletes); and 61\% were "Team Danmark athletes" (mostly elite athletes on the periphery of a senior national team and upcoming talents selected for national junior team squads). The athletes not supported by Team Danmark were national senior or junior team athletes of a high competition level. The qualitative 
part consisted of semi-structured face-to-face interviews $(\mathrm{n}=21)$ and open-ended answers in the questionnaire ( $\mathrm{n}=63)$. The inclusion criteria for interviews were: high performance level (had a competition level that qualified them for one of Team Danmark's support categories or national federation selection at some point), sport (swimming, cycling, badminton) and gender (equal representation). Almost all of the athletes invited for interviews accepted the invitation. The sports represented were: swimming (female $n=4$; male $n=4$ ), badminton (female $n=4$; male $n=4$ ) and cycling (female $n=2$; male $n=3$ ). The age range was between 20 and 32 years. The researcher is a former elite athlete and the (former) "insider" status could influence the research process.

\subsection{Measures}

A multi-dimensional mixed-method design was adopted (Mason, 2006). This is useful because the mixing and linking of methods (questionnaire and different forms of qualitative data) and theoretical approaches/concepts (Sections 1.1,1.2) relating to themes ("knots", i.e. multiple perspectives around the use of analgesics in the working context of sport) provide "multi-nodal" explanations that can enhance our understanding of the sport-related use of analgesics and allow for more comprehensive answers to the research questions.

Questions on analgesics were integrated into a questionnaire assessing elite sport life and elite athletes' views on and experience with legal performance-enhancing drugs and methods (author, 2013). The survey items on analgesics were developed mainly with inspiration from findings in interviews with current and former elite athletes from different sports and existing research in the area (e.g. Roderick, 2006). This qualitatively driven design (Mason, 2006) allows for new (as yet unexplored) quantitative perspectives on the use of analgesics. The questions referred to: Q1: the sport-related use of different types of analgesics (4 items); Q2: reasons for using analgesics (11 items); Q3a: willingness to use analgesics in specific situations among athletes who had not yet used them in the given situation and Q3b: among athletes who had never used analgesics in a sporting context (up to 6 items); Q4a: whether athletes refrain from or minimise the use of analgesics (4 items); Q4b: reasons for refraining from or minimising the use of analgesics (13 items); and Q5: guidance on analgesics (7 items). (See figures and tables for items and scales). 
The qualitative part of this study consisted firstly of open-ended questions in the survey provided in Q2-Q5 to allow participants to elaborate on their answers and an inductive development of themes. Secondly, questions about analgesics were integrated into interview-guidelines developed to gain in-depth knowledge of the elite athletes' lives, including their working conditions and approaches to performanceenhancing strategies in sport (author, 2013). The questions about analgesics were integrated into two areas of the interview-guidelines. Firstly, questions explored the athletes' experiences with and perceptions of the sport-related use of analgesics. The interviews also inquired into the roles of the coaches and other experts for the athletes' sporting lives and practices. Secondly, the interview-guidelines included a discussion-scheme - designed to explore social norms related to performance enhancement. The sportrelated use of, respectively, mild pain relief, NSAIDs and cortisone was included (as three out of 24 performance-enhancing strategies in the discussion-scheme) and discussed based on the athletes' own practice and/or sporting environment.

\subsection{Data analysis}

The data was analysed using SPSS 23. Descriptive data are reported as frequencies and percentages. Biand multivariate nonparametric statistics were used to compare differences and associations between groups of athletes with regard to gender and sport type. Differences were assessed using a chi-square and gamma test, odds ratio risk estimates.

All the qualitative accounts from open-ended answers in Q2-Q5 were all read in-depth - analysed inductively and grouped inductively into themes - and then displayed in a table within each question (Q2Q5) with illustrative quotes within each theme. The interviews were all carried out and transcribed fully by the author. The transcriptions were read in-depth, and areas and narratives about analgesics and injuries were identified. Inductive and deductive reasoning were combined, and thematic coding was performed to identify topics and narratives. The analytic generalisation strategy was inspired by category zooming (Halkier, 2011). This approach can be useful when contradictions, exceptions and processes cannot easily be identified as ideal types and it is relevant to zoom in on single aspects (or categories) in data placed in context. Based on the data, some similarities on a more general level were identified (e.g. almost all had experiences with sport-related use of analgesics). Simultaneously, data showed that zooming in on how it 
was used, particularly "sport-specific issues, gender and meanings of sport-related use" and "issues of guidance, influencers and self-administration of use" would be relevant; and three perspectives are provided (contributing knowledge to the research questions 2-5) in Section 3.6.

\section{Results}

With regard to the participants' characteristics, most of the 696 athletes replying to the questions on analgesics had had long-lasting injures (68\%), and $17 \%$ had had one or more operations due to overload or acute injury (Table 1).

$>>$ Table $1<<$

\subsection{What is athletes' experience with sport-related use analgesics?}

Almost all athletes (93\%) had experience with sport-related pain-relieving products. Half (49\%) of the athletes had used NSAIDs in a sporting context several times, and $18 \%$ had had local cortisone injections at least once (Figure 1).

\section{$>>$ Figure $1<<$}

Using bivariate distributions, differences between groups of athletes were revealed in their sport-related use of analgesics. Female athletes from individual sports were more likely to have used mild pain relief products compared to male athletes from individual sports (87\% vs. $74 \%)(\mathrm{OR} 2.42(1.36 ; 4.31)$;gammavalue:0.42; $\mathrm{p}<0.001$, while male team-sport athletes were more likely to have used NSAIDs compared to female team-sport athletes $(66 \%$ vs. $54 \%)(\mathrm{OR} 1.66(1.05 ; 2.62)$;gamma-value:0.25; $\mathrm{p}<0.037)$.

\subsection{What are the reasons for sport-related use of analgesics?}

The athletes $(93 \%, n=631)$ who had experience of pain-relieving products were asked about their reasons for this sport-related use. The most common reasons were to relieve headaches (82\%) and to be able to compete in an important match despite an injury (64\%). The least frequent reasons were use as an integral part of the routine in the specific sport (4\%) and to reduce bodily stress (13\%) (Figure 2).

$>>$ Figure $2<<$ 
Differences were found between groups of athletes in their reasons for having used analgesics. Team-sport athletes more frequently reported to have used analgesics while injured to be able: to compete in an important match/competition (72\% vs. 57\%)(OR 1.95(1.39;2.72);gamma-value:0.32; $\mathrm{p}<0.000)$; to train or compete to keep their position on the team or have their contract prolonged $(35 \%$ vs. $22 \%)(\mathrm{OR}$ $1.93(1.35 ; 2.74)$; gamma-value: $0.32 ; \mathrm{p}<0.00)$; to compete to qualify for an important match or final $(65 \%$ vs. 35\%)(OR 3.47(2.50;4.82); gamma-value:0.55; $\mathrm{p}<0.00)$; and to relieve soreness $(67 \%$ vs. $53 \%)(\mathrm{OR}$ 1.78(1.29;2.47); gamma-value:0.28; $\mathrm{p}<0.00)$. Adjusting for gender showed that female individual athletes were more likely than male individual athletes to have taken analgesics to compete in an important competition while injured $(62 \%$ vs. 54\%)(OR 1.63(1.04;2.56);gamma-value:0.24, $\mathrm{p}<0.032)$ whereas male team-sport athletes were more likely than female team-sport athletes to have taken analgesics while injured to compete in an important competition $(78 \%$ vs. $64 \%)(\mathrm{OR} 1.99(1,20 ; 3.33)$;gamma-value:0.332; $\mathrm{p}<0.008)$ and to qualify for an important match/final (71\% vs. 58\%)(OR 1.74(1.08;2.80);gamma-value:0.27; $\mathrm{p}<0.028)$. Female athletes reported more frequently on the sport-related use of analgesics to relieve a headache (92\% vs. 75\%)(OR 3.72(2.36;6,11);gamma-value:0.58; $\mathrm{p}<0.00)$.

\subsection{How do specific situations affect athletes' willingness to use analgesics?}

To identify whether reasons for not having used analgesics in specific situations were due to a lack of willingness to use pain-relieving products in this particular situation or if the athlete had not yet been in a given situation that required its use, all of the athletes who had not already used pain-relieving products in a specific situation were asked if they would use them if the situation arose (again) (Figure 3).

\section{$>$ Figure $3<<$}

A majority of the athletes had already used or would (perhaps) be willing to use painkillers in situations of injury: if this allowed them to compete despite an injury (84\%) or if it was deemed necessary to qualify for an important match (78\%). Using pain-relieving medicines solely for performance-enhancing reasons (43\%) was less acceptable within the athlete group. 


\subsection{Do athletes refrain from or minimise the use of pain-relieving medicines? And if so, why?}

In total, $38 \%$ of the athletes reported that they had experienced situations in which they decided to refrain from or minimise a sport-related use of pain-relieving medicines. In contrast, $28 \%$ declared never to have consciously decided to refrain from or minimise the use of pain-relieving medicines, and $18 \%$ reported never to have been in a situation in which it was necessary to refrain from or minimise their use. A minority, $15 \%$ did not know whether they had refrained from or minimised the use of pain-relieving medicines. Refraining from or minimising the use of analgesics was not significantly associated with gender or sport group (or any interactions between these groups) $(\mathrm{n}=691)$.

Athletes who reported having experience of refraining from or minimising the use of analgesics (38\%; $n=265)$ were subsequently asked about their reasons for this decision. The reasons related to: i) trust in/feeling the body; ii) worries about physical and mental side effects; iii) lack of knowledge; and iv) social norms (Figure 4). The most frequent reasons were to be able to 'feel the body' ( $n=175 ; 25 \%$ of total) and trusting in the body's ability to cope with the situation $(n=154 ; 22 \%$ of total).

\section{$>>$ Figure $4<<$}

\subsection{Who provides guidance on the sport-related use of analgesics?}

Only 7\% ( $\mathrm{n}=46)$ reported never to have received any guidance and never themselves to have searched for knowledge within the area of pain-relieving medicines. On average, athletes reported more than two sources of guidance $(2.32(\mathrm{SD}=1.51))$, physiotherapists being the most frequent source $(57 \%)$. One third (34\%) (also) self-administered pain-relieving medicines (Figure 5). In total, 52\% self-administered use and/or obtained and exchanged knowledge with other athletes.

\section{$>>$ Figure $5<<$}

Differences emerged between groups of athletes in their sources of guidance. Individual sport athletes more frequently reported the coach or managers as their source of guidance for analgesics use $(45 \% v s$. $31 \%)($ OR 1.86(1.36;2.55);gamma-value:0.301; $\mathrm{p}<0.001)$; and were less likely to be guided by physiotherapists $(49 \%$ vs. $68 \%)(\mathrm{OR} 0.45(0.33 ; 062)$;gamma-value:-0.379; $\mathrm{p}<0.001)$. Male athletes were 
more likely to obtain knowledge and exchange experience with training mates or others $(37 \%$ vs. $28 \%)(\mathrm{OR}$ 1.49(1.07;2.08);gamma-value:0.20; $\mathrm{p}<0.015)$ and to self-administer analgesics $(38 \%$ vs. $28 \%)(\mathrm{OR}$ 1.61(1.56;2.24);gamma-value:0.23; $\mathrm{p}<0.004)$. However, when adjusting for sport, gender differences were only found between male and female team-sport athletes in exchanging knowledge in the training environment (41\% vs. 23\%)(OR 2.31(1.14;3.78);gamma-value:0.40; $\mathrm{p}<0.00)$ and between male and female athletes from individual sports in their self-administration $(41 \%$ vs. $31 \%)(\mathrm{OR}$ 1.57(1.01;2.46);gamma-value:0.22; $\mathrm{p}<0.043)$.

\subsection{The sport-related use of analgesics, guidance and self-administration: A matter of sport,} gender and the sporting environment/network?

Qualitative data helps to obtain more comprehensive answers to the research questions RQ2-5 (Section 2.2-2.3). This is done, firstly, by providing a more in-depth understanding of gender and sport-specific issues related to the complexity of elite athletes' use of analgesic, including differences in the role of the sporting network/training environment and self-administration; and, secondly linking this with the quantitative data and concepts relating to the same research questions (Section 2.1-2.2), particularly in the discussion (Section 4).

Table 2 provides an overview of the surveyed athletes' elaborations on their considerations when using or refraining from using analgesics in a sporting context, their willingness to use them and guidance ( $n=63)$. It expands the knowledge in relation to Q2-5 by elaborating on specific situations, deliberations about use, considerations of health and personal routines.

\section{$>>$ Table $2<<$}

Almost all the athletes interviewed had experiences with analgesics in training or competition. However, the use was often described as a non-habitual practice. Athletes dissociated themselves from systematic use or use in certain situations. What the athletes (with experience of competing injured using analgesics) had judged in the past as a competition 'important enough' to legitimise the use of analgesics to be able to compete while injured often related to a sense that it was important for them to compete that particular time rather than what one might regard as an "important competition" (e.g. a World Championship). 
Despite these similarities in experiences with and deliberations on the use of analgesics, the interviews illustrated some sport-specific patterns and issues in use of analgesics and in whether, how, when or which support personnel played a role in the use of analgesics (the athletes' degree of autonomy varied considerably) and gender similarities. Perspectives (Section 2.3) within each sport are described below.

\subsubsection{The impact of sport socialisation on the use of analgesics in swimming. The 'persuasive' coach}

Occasionally, the guidance from sporting networks can be seen more as exerting pressure on athletes to use analgesics with and without an injury (Section 1.1; Table 2). Several of the swimmers interviewed were hesitant to use analgesics; sometimes this was described as an integral part of growing up. The coach's persuasive argumentation, however, influenced many swimmers to follow his instructions - or some of them. Gender similarity in approaches to analgesics (and supplements) was prominent. However, family socialisation made the coach's advice barrier-breaking. After the coach had realised that many of the swimmers would prefer not to take pills (in this case referring to both analgesics and new legal supplements), he sought to alter the athletes' way of thinking. Below is a female athlete's description of the coach's arguments and how she took these into consideration:

"Do you know that all of your competitors take all sorts of different supplements?" - not hinting at EPO or anything - but what one takes, and how we then could think of saying 'we do not want this' and then believe we could be as good as them?...And this I thought about, I felt it made sense - because I do not see myself as being better than my competitors - that I could do it without help! (female, swimming)

In response the swimmer started using analgesics as part of a 'recovery routine' - although sometimes she would just tell the coach she had taken it. Not all athletes faced the same demand from the coach, but this difference in interaction with the coach can only partly explain the differences in reaction. These also depended on family and sport socialisation and the degree of autonomy offered. For example, a male swimmer was hesitant about taking medicine and refrained even from asthma medicines - despite having been granted permission to use these. He stressed that if the coach asked him to use analgesics to reduce muscle pain during competitions, he would require more information. Self-administration was seldom mentioned, but one female swimmer had adopted her own routine: she would occasionally - at home - use analgesics to relax the body to be able to sleep during hard training periods. 


\subsubsection{The sport-related use of analgesics and self-administration in the badminton environment}

In the badminton environment one athlete was mentioned by several players because he 'walked the line' for the sport and continuously used a variety of pills to be able to train and compete despite injuries. Although other players understood this athlete's willingness to run risks and make sacrifices for the sport, the number of pills he took was considered too extensive. However, a female athlete explained that the use of ibuprofen was common (particular during competitions): the physiotherapist provided the pills, but many would also self-administer them. She had also competed on these herself, but only the "light ones" - pills she described as harmless and solely for the purpose of relieving pain, not removing it. The notion that pills like those containing ibuprofen were harmless because they still left the athlete with some pain and thus a sense of bodily control - was also stressed by other athletes (also from other sports). In this context, some athletes would also use them during competitions to shift the focus from the pain or a minor injury to performing well. Some athletes would self-administer analgesics when they disagreed (or expected to disagree) with the physiotherapist's advice or felt their recovery from injury was too slow.

...this was in periods when I was in pain. Then I had to take some pills to train. And also if I had injuries and the physiotherapists' (treatment) was not as quick as I thought it should be. Then I perhaps started on a course of ibuprofen treatment without them being involved. And, of course, I know one should not be training $100 \%$ when on pills, but I made sure, of course, to cut down a bit. But I did train. (female, badminton)

The findings suggest that some female players' practices concur with some of the men's in this training environment. This contradicts a male athlete's representation of gender differences who brought up the issue of virility when discussing analgesics and guidance in his sport, explaining that he would expect the "girls" to go to the physiotherapist (and follow his/her advice) - but "boys" would act differently:

...for example, many of us boys just refrain from going to the physiotherapist if we know he would say, "It is stupid to go to this competition." Then we would not consult him - because there isn't any reason to know this! We will just take a couple of pills instead, then it's okay. (male, badminton)

There were, however, differences between individual players in their approaches to analgesics. 


\subsubsection{The in-competition use of analgesics in cycling, influencing sporting networks and self- administration}

The cyclists interviewed varied greatly in their experiences of and approaches to the sport-related use of analgesics. Gender differences seemed dominant among the cyclists interviewed: the male cyclists were more experienced and open towards the sport-related use of analgesics than the female cyclists. However, the low number of interviews in cycling - and the fact that the cyclists interviewed were members of different teams and environments - suggests that no conclusions should be drawn about gender. Particularly cyclists mentioned in-competition use as a means of reducing pain (to enhance performance) along with prophylactic use. The male cyclists expected such use to be widespread: one cyclist describes how others could be inspired by "insiders" to "try it out" when hearing stories about other riders using them, for example of an extensive in-competition use of a well-known successful cyclist. This cyclist selfadministered their use and the doses himself. He tried only to do this during important competitions but found that it easily became part of the competition routine:

It easily becomes something like, okay, there I was riding fast, and at that time I took 2-3 of these pills (aspirin). And then it is like you need to have it again to be able to ride fast. It is psychological somehow (male, cycling).

For another male cyclist an "in-competition" routine with analgesics combined with caffeine was introduced by the staff in a new team. However, during the first years of his employment he was 'lucky' if he was given any, but this gradually changed. He now sought to reduce their use by avoiding to take them if 'not necessary' - as in the many races in which he was only in the peloton.

Local cortisone injections are common (Figure 1). Some of the cyclists mentioned cases of cyclists being given cortisone in-competition for a 'sore knee' ('simulating' an injury).

\section{Discussion}

The study was designed to explore the complexity of the sport-related use of analgesics in the working context of sport, investigating in particular elite athletes' experience of and willingness to take analgesics in order to train or compete despite injury, their use of analgesics for other reasons, as well as athletes' approaches to their use, to sources of guidance and to self-administration. 
The study applies a multi-dimensional mixed-method design (Sections 2.2-2.3,3.6). Data is linked and discussed under the following indicative headings: "Sport-related use of analgesics: "Walking the line?" (RQ: 1-3); “The social and cultural context of use of analgesics: 'One for the team'?" (RQ: 2,4); "Sportrelated use of analgesics: A matter of gender?" (RQ: 2,5); "Normalisation: Just part of the routine in the sport?” (RQ: 2-5); “No pain, no gain - or feeling and ignoring body pain?” (RQ: 3,4); and "Guidance on analgesics or self-administration of use?" (RQ: 2,4,5).

\subsection{The sport-related use of analgesics: Walking the line?}

Sport is a precarious profession, and the basic characteristics of work in elite sport are formed from factors associated with work-related presenteeism and the corresponding expectations in the working environment (Section 1.2). In line with the findings of Mayer and Thiel (2018) many athletes showed indications of work-related presenteeism. In fact, the high proportion of athletes who had taken analgesics to train or compete while injured, as well as those who reported to be willing to do so in certain situations, and those who used analgesics for other purposes without injuries (Figure 2,3; Section 3.6) suggests that a majority of athletes would be willing to 'walk the line'. This is particularly so in situations when injuries may threaten sporting success or an athlete's career.

The finding that almost all of the athletes had experience of a sport-related use of analgesics in different situations was expected, considering i) the high proportion of athletes who had had small or longlasting injuries and sport-related operations (Table 1); ii) the risk culture existing in sport, which may involve sickness presenteeism (Section 1.1-1.2); iii) the well-established in-competition use without injuries (Joslin et al., 2013); and iv) the known high prevalence of particularly NSAIDs across a variety of sports (Alaranta et al., 2006).

Various types of the sport-related use of analgesics may be considered indications of work-related presenteeism (Section 1.2). The in-competition practices and routines involving the use of analgesics to enhance performance were adapted by some athletes (Figure 2, Section 3.6.1-3), however, considering the working conditions in sport (Section 1.1-1.2) one might expect even more athletes to have used analgesics to enhance performance without injuries. An explanation might be that some athletes would prefer to know that they (and not a drug) are responsible for a good performance (Overbye, 2013). Further, analgesics are 
not necessarily performance enhancing, and they can also have reverse effects on performance (Mackey et al., 2012,\#12).

In line with Safai (2003) the study show that some athletes carefully consider situational aspects, for example, when it is appropriate to use analgesics (\#8\#,14,\#15; Section 3.6.1-2). In addition, many athletes deliberately refrain from using analgesics or at least minimise their use (Sections 3.4; 3.6.1-3), for example, for reasons related to: trust in/feeling the body, side-effects, knowledge and social norms (Figure 4). This shows norms and attitudes towards a sport-related use of analgesics among some athletes and their sporting network (\#9,\#11,\#14; Section 3.6.1-2). It also confirms the existence of a 'culture of precaution' interacting with the 'culture of risk' (Safai, 2003) or that absenteeism is also present (Mayer and Thiel, 2018).

\subsection{The social and cultural context of the use of analgesics: 'One for the team'?}

Mayer and Thiel (2018) showed a higher preparedness among handball players compared with track-andfield athletes for presenteeism at work, including a willingness to 'play' despite having to take painkillers. Broadly similar, the current study found that team-sport athletes were more likely to have used analgesics when injured to be able to: i) compete in an important match; ii) qualify for an important match/final; or iii) keep the position on the team or have the contract prolonged. An explanation might be found in the differences in how risk cultures manifest themselves in sporting disciplines (Schnell et al, 2014). The specific social and cultural context and the complex interactions and interdependencies will influence athletes' responses to drug use (Section 1.2). These may be explained by differences in the organisation of work influencing the way athletes are socialised and their discourses and practices with regard to substance use (Ohl et al., 2015). Further, social norms and discourses on showing willingness as well as the expectation and pressures to use analgesics to compete when injured (Roderick, 2006) might be more prominent in team sports, in which the success of the team (other athletes, sports personnel and the club) may be dependent on an athlete's ability to play matches.

Further, the differences in injury risk patterns (Hägglund et al., 2016) and the higher prevalence of long-term injuries among the team-sport athletes surveyed (Table 1) may suggests increased vulnerability and exposure to concrete pressure situations for team-sport athletes. 


\subsection{The sport-related use of analgesics: A matter of gender?}

In line with Mayer and Thiel (2018), the results suggest that gender seldom plays a role in work-related presenteeism. However, some exceptions were identified, with female athletes from individual sports more likely than male individual athletes to have used analgesics to compete when injured in an important competition. While male team-sport athletes were more likely than female team-sport athletes to have taken analgesics to compete with an injury in situations related to ensuring sporting success or be available for an important match. Further, the interviews indicate some gender differences in male discourses on this topic (Section 3.6.2-3). However, the interview findings suggest that male and female athletes training in the same sporting environment share more similarities than differences in their approaches to the sportrelated uses of analgesics. Gender similarity in the internalisation of risk cultures and willingness to compete injured was expected (Mayer and Thiel, 2018; Mayer et al., 2018).

An explanation for gender similarities might be found in the strong influence of sport socialisation processes through which both male and female athletes learn to have the 'right attitude' with regard to the normalisation of risk, living with pain and championing competing injured (Charlesworth and Young, 2006). Gender-specific responses to analgesics may, however, manifest themselves in other areas since athletes' responses to injury and pain may be a product of both sport and gender socialisation processes. While sport socialisation processes increase gender equality, gender socialisation processes reflect more traditional gender roles that can lead athletes to adapt different sense-making strategies about injury, pain and analgesics, for example how - or whether - they feel they should accept, display and understand injury (Charlesworth and Young, 2006).

\subsection{Normalisation: Just part of the routine in the sport?}

Although studies illustrate how analgesics are an integral part of the routine in sports (Roderick, 2006; Waddington and Roderick, 2002; Section 1.2), relatively few of the athletes surveyed agreed that this was part of the routine in their particular sport. One explanation for this could be that routines are normalised and thus scarcely perceptible. Awareness of whether the decision to use pain-relieving medicines is because it is just part of routine may be part of a neutralisation strategy or technique (Sykes and Matza, 1957) or rationalised by athletes through other reasons (Figure 2) such as their use for reducing stress in 
the body. Further, the use of analgesics is embedded as a routine, ritual or habit - or derives from expectations in some environments (Table 2; \#6,\#7,\#15; Section 3.6.1-3). Tscholl and colleagues (2015) found an overuse of NSAIDs prior to all FIFA World Cup matches and suggested that players used these without injuries. In the current study, the in-competition use of analgesics to reduce or remove pain or forget small injuries seems routinized for some athletes (Section 3.6.2-3) while some acknowledged that such a routine worked more as "placebo" (\#7). Further, the prophylactic use belongs in various ways to the rituals and 'routines', for example as a way of reducing bodily stress (Figure 2; Section 6.3.1-2) "just to be sure" (\#6,\#7) or to get the body warmed up (\#2).

\subsection{No pain, no gain - or feeling and ignoring body pain?}

Pain and injuries are predictable and integral occupational risks in athletes' working lives (Section 1-1.1). Although analgesics are key to pain management in sport (Hainline et al., 2017), some athletes hesitate to use them for reasons often related to the belief that the body can or should handle pain itself (Figure 4,Table 2; Section 3.6.1). In this respect, some athletes prefer to be able to feel the pain, and so may train and compete when injured without taking analgesics (\#3,\#4,\#9,\#10). Similarly, for some athletes, refraining from (or minimising) the use of analgesics had to do with being able to feel and control the body and pain to avoid a breakdown (\#3,\#11,Figure 4). The notion of still being able to feel some pain and retain bodily control was also used, however, as a normalisation strategy to categorise 'light' analgesics as 'harmless' (Section 3.6.2). An explanation for athletes wishing to (still) feel bodily pain might be found in the predictability and normalisation of pain and injury in sport culture (Nixon, 1996; Charlesworth and Young, 2006).

\subsection{Guidance on analgesics or self-administration of use?}

Different actors potentially play a role with regard to sport-related drug use (Section 1.2). The ways sports medicine clinicians interact are critical (Section 1.1). The results show that athletes often had several sources of guidance on the use of analgesics and that the roles of doctors, coaches/managers or physiotherapists varied between sports (Figure 5,\#1,\#16,\#17, Section 3.6.1-2). Further, situational aspects 
in interactions with sporting networks led to changes in practices around analgesics, for example with a new coach, a new team/employer or role model (Sections 3.6.1; 3.6.3).

Although guidance from medical experts seems pivotal for reducing health risks, the precarious working environment and common norms of sport may counteract opportunities for health protection (Section 1.1-1.2). For example, an athlete was pressured by the coach to use analgesics, whose reasoning was that he was the best and should be a 'good role model' (\#5). This confirms how, in some environments, using analgesics is considered a matter of showing the 'right attitude', and how athletes risk stigmatisation if not fulfilling these common sporting norms (Roderick, 2006). Broadly similar the example of the 'persuasive coach' (Section 3.6.1) illustrates how common aspects of 'sport ethics' were used to convince hesitating athletes to use analgesics and supplements. In this case, the coach's authority seemed pivotal in influencing norms and practices around non-therapeutic or prophylactic uses of analgesics in the environment. A recent report (Tingstad and Petersen, 2020) illustrates the pivotal role of certain former national coaches in enforcing sickness presenteeism on swimmers involving use of analgesics and reveals extreme working conditions with lack of care for the swimmers' health and wellbeing.

However, Murphy and Waddington (2007) argue for the notion of 'risk transfer', suggesting that responsibilities and risks are shared or transferred rather than athletes being victims or exploited by their environment. Study results often seem to support this notion with various forms of self-administration being examples of 'risk transfers'. The finding that half of the athletes (also) self-administer analgesics and/or obtain knowledge and exchange experiences with other athletes confirm that athletes may treat their symptoms themselves (Malcolm, 2009) and act as 'mini experts' in the sporting environment (Roderick, 2006). Athletes may search for knowledge and navigate through expert advice, like a male athlete (\#18) who formulated his strategy as: "Listen to everyone: make up my own mind". The self-administration of analgesics involves risks (Warden, 2009) and may be influenced by subcultural norms and traditions in the specific sporting environment. Broadly similar with other research (Malcolm, 2009; Pike, 2006) some athletes disregard medical advice or avoid consulting medical experts when it is anticipated they will recommend rest but self-medicate (Section 3.6.2). 


\section{Conclusion}

Applying a multi-dimensional mixed-method approach and exploring different questions about the sportrelated use of analgesics contributes to our understanding of the complexity of this issue in the working context of sport and adding to our knowledge of sickness presenteeism and absenteeism in elite sport. In conclusion, the sport-related use of analgesics is prevalent. Analgesics were integrated into the sporting routines and used for various reasons in- and out-of-competition and with and without injury. Most athletes had already used or would be willing to use analgesics to be able to train or compete when injuries may threaten their careers or sporting success. Simultaneously, many athletes refrained from using or sought to minimise their sport-related use of analgesics for reasons related to: trust in and feeling the body; worries about the physical and mental side-effects; their lack of knowledge about certain substances; and social norms. The study identified sport- and culture-specific patterns and gender similarities in their approaches to the uses of analgesics. Furthermore, it showed how interactions with sporting networks play a key role in influencing norms and practices in training environments, with athletes navigating in various ways through the advice given to them, through the requirements of their sporting network and through selfadministered use.

An important study limitation is that the interviews only included elite athletes from individual sports (Section 2.1,3.6). The inclusion of team-sport athletes would have added further nuances to sport-specific issues, particularly to the in-competition use of analgesics when injured and on how team dynamics or the organisation of work may have an impact on the use of analgesics. Other limitations relate to sample heterogeneity (all high performance athletes from one single country) and reliance on self-reporting. Findings are not representative a specific sport. Further, the cross-sectional design does not allow for identification of potential changes in athletes' sport-related use of analgesics over the course of their careers nor allow for observation of developments/changes within dynamic sporting environments. Future studies could apply a longitudinal mixed-method design to explore the complexity of sport-related use of analgesic, specific routines and issues within different sporting disciplines (in different countries) and circumstances/events influencing changes in presenteeism and absenteeism cultures. Further, studies could explore development/changes in use of analgesics and perceptions during an athlete's career, considering 
the impact of the organisation of work, of change in coaches/medical staff, of career- and health obstacles/events, and of transitioning into another working environment.

\section{Notes}

1:The Danish healthcare model is universal with free healthcare for all citizens. Hansen and Andersen (2008) suggested that the Danish welfare state - and its flexicurity model combining flexibility and security - might decrease sickness presenteeism.

\section{References}

Alaranta A, Alaranta H, Heliövaara M, et al. (2006). Ample use of physician-prescribed medication in Finnish elite athletes. International Journal of Sports Medicine;27:919-25.

Anderson L and Jackson S (2013). Competing loyalties in sports medicine: Threats to medical professionalism in elite, commercial sport. International Review for the Sociology of Sport. 48(2):238-256.

Beamish R and Ritchie I (2006) Fastest, Highest, Strongest: A Critique of High-performance Sport. New York: Routledge

Bette KH (2004). Biographical Risks and Doping. In: Doping and Public Policy eds. J.Hoberman and V.Møller. Odense:University of Southern Denmark.

Charlesworth $\mathrm{H}$ and Young K (2006). Injured female athletes. Experimental accounts from England and Canada. In: Pain and injury in sport. Social and ethical analysis. Eds. S.Loland, B.Skirstad and I.Waddington. London: Routledge.pp.89-106.

Cottler L, Abdallah AB, Cummings SM, et al. (2011). Injury, Pain, and Prescription Opioid Use Among Former National Football League (NFL) Players. Drug Alcohol Depend.116(1-3):188-194.

Didymus FF and Backhouse $\mathrm{S}$ (2020). Coping by doping? A qualitative inquiry into permitted and prohibited substance use in competitive rugby. Psychology of Sport \& Exercise.49 https://doi.org/10.1016/j.psychsport.2020.101680

Dunn, M (2015). The importance of understanding motives for prescription substance use and misuse in sport. Performance Enhancement and Health 3(2):102-104.

Gouttebarge V, Aoki H, Ekstrand J, et al. (2015). Are severe musculoskeletal injuries associated with symptoms of common mental disorders among male European professional footballers? Knee Surg Sports Traumatol Arthrosc. 24(12);3934-3942

Hägglund M, Waldén M and Ekstrand J (2016) Injury recurrence is lower at the highest profes- sional football level than at national and amateur levels: Does sports medicine and sports physiotherapy deliver? British Journal of Sports Medicine 50: 751-758. 
Hainline B, Derman W, Vernec A, et al. (2017). International Olympic Committee consensus statement on pain management in elite athletes. Br J SportsMed,51:1245-1258.

Halkier, B (2011). Methodological Practicalities in Analytical Generalization. Qualitative Inquiry 17(9)787-797

Hansen, CD and Andersen JH (2008). Going ill to work - What personal circumstances, attitudes and work-related factors are associated with sickness presenteeism? Social Science \& Medicine 67:956964

Johns, G (2010). Presenteeism in the workplace: A review and research agenda. Journal of Organizational Behavior.31:519-542

Joslin J, Lloyd JB, Kotlyar T, et al. (2013). NSAID and other analgesic use by endurance runners during training, competition and recovery. S Afr J SportsMed;25(4):101-104

Law, G and Bloyce D (2019) 'Pressure to play?' A sociological analysis of professional football managers' behaviour towards injured players, Soccer \& Society, 20(3):387-407

Lundberg TR and Howatson G (2018). Analgesic and anti-inflammatory drugs in sports: Implications for exercise performance and training adaptations. Scand J Med Sci Sports.28:2252-2262.

Mackey AL, Mikkelsen UR, Magnusson SP, et al. (2012). Rehabilitation of muscle after injury - the role of anti-inflammatory drugs. Scand J Med Sci Sports. 22:e8-e14

Malcolm, D (2009). Medical uncertainty and clinician-athlete relations: The management of concussion injuries in rugby union? Sociology of Sport Journal, 26(2):191-210.

Malcolm, D and Scott, A (2014). Practical responses to confidentiality dilemmas in elite sport medicine. Br J Sports Medicine 48:1410-1413

Mason, J (2006). Mixing methods in a qualitatively driven way. Qualitative Research, 6(1):9-25.

Mayer J, Giel K.E, Malcolm D, et al. (2018). Compete or rest? Willingness to compete hurt among adolescent elite athletes. Psychology of Sport \& Exercise 35:143-150.

Mayer J and Thiel A (2018). Presenteeism in the elite sports workplace: The willingness to compete hurt among German elite handball and track and field athletes. International Review for the Sociology of Sport. 53(1):49-68.

Morelli KM, Brown LB and Warren G (2018). Effect of NSAIDs on Recovery From Acute Skeletal Muscle Injury. A Systematic Review and Meta-analysis. American J Sports Med. 46(1):224-233.

Murphy, P and Waddington, I (2007). Are Elite Athletes Exploited? Sport in Society, 10(2):239-255.

Nixon HL (1996). Explaining pain and injury attitudes and experiences in sports in terms of gender, race, and sports status factors. Journal of Sport \& Social Issues. 20:33-44.

Ohl, F, Fincoeur, B, Lentillon-Kaestner, V, et al. (2015). The socialization of young cyclists and the culture of doping. International Review for the Sociology of Sport, 7:865-882.

Overbye M (2018). An (un)desirable trade of harms? How elite athletes might react to medically supervised 'doping' and their considerations of side-effects in this situation. International Journal of Drug Policy, 55:14-30. 
Overbye, M (2013). Doping og anti-doping i kontekst. En analyse af eliteidratsudøveres oplevelse af anti-doping policy, betydende faktorer for til- eller fravalg af doping, (u)lovlige prastationsfremmende midler, granser og dilemmaer. $\mathrm{PhD}$ thesis. University of Copenhagen, Denmark.

Pike, E (2005). Doctors just say "rest and take ibuprofen": A critical examination of the role of "nonorthodox" health care in women's sport. International Review for the Sociology of Sport, 40:201-219

Ristolainen L, Kettunen JA, Kujala UM, et al. (2012). Sport injuries as the main cause of sport career termination among Finnish top-level athletes, European Journal of Sport Science.12:274-282

Roderick M (2006). Adding insult to injury: Workplace injury in English professional football. Sociology of Health and Illness. 28(1):76-97.

Roderick M, Waddington I and Parker G (2000). "Playing hurt": Managing injuries in English professional football. International Review for the Sociology of Sport. 35:165-180.

Rhodes, T (2009). Risk environments and drug harms: A social science for harm reduction approach. International Journal of Drug Policy, 20:193-2

Safai P (2003). Healing the Body in the "Culture of Risk": Examining the Negotiation of Treatment Between Sport Medicine Clinicians and Injured Athletes in Canadian Intercollegiate Sport. Sociology of Sport Journal. 20:127-146.

Sanders G and Stevinson C (2017). Associations between retirement reasons, chronic pain, athletic identity, and depressive symptoms among former professional footballers, European Journal of Sport Science. 17(10):1311-1318

Schnell A, Mayer J, Diehl K, et al. (2014). Giving everything for athletic success! - Sports-specific risk acceptance of elite adolescent athletes. Psychology of Sport and Exercise. 15:165-172.

Sykes, G and Matza, D (1957). Techniques of neutralization: a theory of delinquency. American Sociological Review, 22:664-673.

Thing LF (2006). "Voices of the broken body." The resumption of non-professional female players' sports careers after anterior cruciate ligament injury. The female player's dilemma: is she willing to run the risk? Scand J Med Sci Sports.16:364-375

Tingstad, T and Petersen, HQ (2020). Undersøgelse af forholdene for elitesvømmere i Dansk Svømmeunion. Kammeradvokaten:Report.

Tscholl P, Vaso M, Weber A, et al. (2015). High prevalence of medication use in professional football tournaments including the World Cups between 2002 and 2014: a narrative review with a focus on NSAIDs. Br J Sports Med.49:580-582.

Turner AP, Barlow JH and Heathcote-Elliott C (2000). Long term health impact of playing professional football in the United Kingdom. Br J Sports Med.34:332-337

Vernec A, Slack A, Harcourt PR, et al. (2019). Glucocorticoids in elite sport: current status, controversies and innovative management strategies - a narrative review. Br J Sports Med.Epub.doi:10.1136/ bjsports-2018-100196 
von Rosen P and Heijne A (2018). Substantial injuries influence ranking position in young elite athletes of athletics, cross-country skiing, and orienteering. Scand J Med Sci Sports.28:1435-1442.

Waddington I and Roderick M (2002). Management of medical confidentiality in English professional football clubs: Some ethical problems and issues. Br J Sports Med. 36:118-123.

Warden SJ (2009). Prophylactic misuse and recommended use of nonsteroidal anti-inflammatory drugs by athletes. Br J Sports Med;43:548-549.

Wiese-Bjornstal DM (2010). Psychology and socioculture affect injury risk, response, and recovery in high-intensity athletes: a consensus statement. Scand J Med Sci Sports. 20:103-111 
Table 1: Participants' characteristics

\begin{tabular}{|c|c|c|c|c|c|}
\hline \multirow[t]{3}{*}{$\mathrm{N}=696^{\dagger}(\mathrm{N}=775)$} & \multirow[b]{3}{*}{ Total } & \multirow{3}{*}{$\begin{array}{c}\begin{array}{c}\text { Team/ball } \\
\text { sports }\end{array} \\
\text { Team sport }\end{array}$} & \multicolumn{3}{|c|}{ Sport type } \\
\hline & & & $\begin{array}{c}\text { Speed and } \\
\text { power sports }\end{array}$ & $\begin{array}{l}\text { Endurance } \\
\text { sports }\end{array}$ & $\begin{array}{l}\text { Motor-skill } \\
\text { sports }\end{array}$ \\
\hline & & & \multicolumn{3}{|c|}{ Individual sport } \\
\hline Sport type & $100 \%$ & $47 \%$ & $24 \%$ & $17 \%$ & $12 \%$ \\
\hline \multirow{2}{*}{ Gender } & $59 \%$ & $57 \%$ & $62 \%$ & $63 \%$ & $59 \%$ \\
\hline & $41 \%$ & $43 \%$ & $38 \%$ & $37 \%$ & $41 \%$ \\
\hline Mean age (SD) & $21.79(5.60)$ & $21.13(5.03)$ & $22.10(5.80)$ & $22.02(5.28)$ & $23.41(7.26)$ \\
\hline Small injury $\ddagger$ & $93 \%(77 \%)$ & $97 \%(84 \%)$ & $92 \%(81 \%)$ & $92 \%(70 \%)$ & $82 \%(54 \%)$ \\
\hline $\begin{array}{l}\text { A long-lasting injury (kept you from } \\
\text { sport for }>3 \text { weeks) })^{\ddagger}\end{array}$ & $68 \%(35 \%)$ & $78 \%(42 \%)$ & $67 \%(36 \%)$ & $57 \%(26 \%)$ & $47 \%(15 \%)$ \\
\hline $\begin{array}{l}\text { An operation due to overload/ acute } \\
\text { injury } \ddagger\end{array}$ & $17 \%(8 \%)$ & $21 \%(10 \%)$ & $20 \%(8 \%)$ & $8 \%(4 \%)$ & $11 \%(2 \%)$ \\
\hline $\begin{array}{l}\text { A longer period of time constantly ill } \\
\text { (e.g. cold or throat inflammation })^{\ddagger}\end{array}$ & $48 \%(33 \%)$ & $45 \%(30 \%)$ & $45 \%(28 \%)$ & $66 \%(50 \%)$ & $41 \%(25 \%)$ \\
\hline $\begin{array}{l}\text { Sick for a longer period of time }(\text { kept } \\
\text { you from sport for }>3 \text { weeks) })^{\ddagger}\end{array}$ & $16 \%(5 \%)$ & $14 \%(4 \%)$ & $14 \%(6 \%)$ & $26 \%(7 \%)$ & $14 \%(2 \%)$ \\
\hline $\begin{array}{l}\text { Been in overtraining (e.g. longer period } \\
\text { with excessive fatigue, heavy muscles, } \\
\text { decreased performance, change in } \\
\text { sleeping patterns and concentration })^{*}\end{array}$ & $63 \%(39 \%)$ & $66 \%(41 \%)$ & $63 \%(41 \%)$ & $63 \%(35 \%)$ & $47 \%(28 \%)$ \\
\hline \multicolumn{6}{|c|}{$\begin{array}{l}\text { T The percentages illustrated in the table are those of the } 696 \text { athletes replying to the survey questions on analgesics. The } \\
\text { survey questions on analgesics were placed at the very end of the very long questionnaire, and athletes were free to skip } \\
\text { the questions if they liked and withdraw from the survey. } 79 \text { of the } 775 \text { athletes decided not answer any of the questions } \\
\text { on analgesics. Thus, participant characteristics of these athletes are not included in Table } 1 \text {. } \\
\text { Note: Age range } 13 \text { to } 46 \text { years of age ( } 3 \% \text { below } 16 \text { years of age. } 19 \% \text { between } 16 \text { and } 17 \text { years old; } 16 \% \text { between } 18- \\
19 \text { years old; } 22 \% 20-23 \text { years old; } 22 \% 24-29 \text { years old, } 16 \% 30-39 \text { years old, } 1 \% 40 \text { years and older). } \\
\ddagger \text { The numbers in parentheses refer to the percentage of athletes who had this experience more than once } \\
\text { * Overtraining (like injuries) reduces the athlete’s work productivity (performance level) and can influence mental health. This } \\
\text { condition may be linked to (sickness) presenteeism. This is because the overtraining syndrome (the medical condition) } \\
\text { results from the athlete ignoring body signals of excessive fatigue, tiredness and stress over a long period of time and } \\
\text { continuing to train regardless, without sufficient time to recover. }\end{array}$} \\
\hline
\end{tabular}




\begin{tabular}{|c|c|c|}
\hline & Themes & Example of quote \\
\hline \multirow{7}{*}{$\begin{array}{l}\text { Q2: } \\
\text { Reasons for } \\
\text { sport-related } \\
\text { use } \\
(n=21)\end{array}$} & $\begin{array}{l}\text { Elaboration on the } \\
\text { product or the } \\
\text { frequency of use (9) }\end{array}$ & $\begin{array}{l}\text { \#1: I have had painkillers on prescription from the doctor, e.g. Tramadol. These did not } \\
\text { help, so I used painkillers although they did not help either (female, TS) }\end{array}$ \\
\hline & $\begin{array}{l}\text { Elaboration on } \\
\text { situation (5) }\end{array}$ & $\begin{array}{l}\text { \#2: Particularly in connection with games where knocks and similar things made it difficult } \\
\text { to get the body warmed up (female, TS) }\end{array}$ \\
\hline & $\begin{array}{l}\text { Train or compete hurt, } \\
\text { but not on pain- } \\
\text { relieving medicines (2) }\end{array}$ & $\begin{array}{l}\text { \#3: I have trained despite having minor injuries but without painkillers because I believe } \\
\text { that pain is the body's way to tell you how it feels. When using painkillers, you are not } \\
\text { aware of how bad it is - and I would like to feel this, so I can avoid more severe injuries } \\
\text { (although I would play anyway) (male, TS) }\end{array}$ \\
\hline & $\begin{array}{l}\text { Change over time } \\
\text { (less than earlier) (2) }\end{array}$ & $\begin{array}{l}\text { \#4: I only use very few pain relievers now, but I did use a lot when I was younger. I prefer } \\
\text { to feel when/that it hurts, so I can feel my limit. (female, MS) }\end{array}$ \\
\hline & $\begin{array}{l}\text { Pressure from coach } \\
\text { (1) }\end{array}$ & $\begin{array}{l}\# 5 \text { : I am being pressured by our national coach to play because I am the best and should } \\
\text { be a role model for the others, he says (male, MS) }\end{array}$ \\
\hline & Routine (1) & $\begin{array}{l}\text { \#6: It is part of the routine in my sport, but not part of the routine in my club, where we } \\
\text { normally are not allowed to play on pain-relieving medicines (male, TS) }\end{array}$ \\
\hline & Habit (1) & $\begin{array}{l}\text { \#7: Sometimes the placebo effect has an effect. That is, one takes pain-relieving } \\
\text { medicines for small injuries before the game, and when the game has started, one } \\
\text { "forgets" the pain. In such situations it probably would not have been necessary because } \\
\text { one's focus in on the game and not on the injury (male, TS) }\end{array}$ \\
\hline \multirow{2}{*}{$\begin{array}{l}\text { Q3: } \\
\text { Willingness } \\
(n=6)\end{array}$} & $\begin{array}{l}\text { Conditions when } \\
\text { answering the } \\
\text { question (5) }\end{array}$ & $\begin{array}{l}\text { \#8: It depends } 100 \% \text { on the situation, e.g. what competition and how important it is } \\
\text { (female, MS) }\end{array}$ \\
\hline & Would never use (1) & $\begin{array}{l}\text { \#9: I would never use pain relievers, I would just carry on playing without, and if the pain } \\
\text { becomes too unbearable, I would stop. Which I would not be able to feel if anaesthetised } \\
\text { (male, SP) }\end{array}$ \\
\hline \multirow{6}{*}{$\begin{array}{l}\text { Q4: } \\
\text { Reasons for } \\
\text { minimising } \\
\text { or refraining } \\
\text { from use } \\
(n=16)\end{array}$} & Others (7) & $\begin{array}{l}\text { \#10: It has seldom been so serious, and I have mostly just played with whatever there } \\
\text { was in the way of injuries and then looked at it after the game or something (male, TS) }\end{array}$ \\
\hline & $\begin{array}{l}\text { Risk of worsening the } \\
\text { situation (3) }\end{array}$ & $\begin{array}{l}\text { \#11: It can create severe or chronic harm if one trains oneself to pieces without feeling it } \\
\text { (female, ES) }\end{array}$ \\
\hline & $\begin{array}{l}\text { Negative effect on } \\
\text { strength (2) }\end{array}$ & $\begin{array}{l}\text { \#12: It is restrictive for building strength to use, for example ibuprofen. It reduces the } \\
\text { effects of training and aggravates the damaged area (female, SP) }\end{array}$ \\
\hline & When it feels right (2) & $\begin{array}{l}\text { \#13: I only use painkillers if it feels like the right thing to do. But I have thought about it } \\
\text { more lately since several football players have fallen over on the pitch (male, TS) }\end{array}$ \\
\hline & $\begin{array}{l}\text { Reduce long-term use } \\
\text { (1) }\end{array}$ & $\begin{array}{l}\text { \#14: Because I have used the substance over a long period of time, but felt that I should } \\
\text { cut down (for health reasons) even though the pains were still present (male, ES) }\end{array}$ \\
\hline & $\begin{array}{l}\text { Systematic use } \\
\text { despite knowledge of } \\
\text { risks (1) }\end{array}$ & $\begin{array}{l}\text { \#15: Risk of worsening the situation if one trains on pain relievers. But I take pain relievers } \\
\text { after training, if necessary, during a period of injury to recover faster (but it seldom } \\
\text { happens) (female, SP) }\end{array}$ \\
\hline \multirow{3}{*}{$\begin{array}{l}\text { Q5: } \\
\text { Guidance } \\
(\mathrm{n}=20)\end{array}$} & $\begin{array}{l}\text { Family members with } \\
\text { expert knowledge (6) }\end{array}$ & \#16: Doctors, nurses, dentists in family. \\
\hline & $\begin{array}{l}\text { Elaboration of other } \\
\text { expert groups (8) }\end{array}$ & \#17: Pharmacy/pharmacist (5); chiropractor (2); Anti-doping Denmark/national team (1). \\
\hline & $\begin{array}{l}\text { Elaboration of self- } \\
\text { administering (6) }\end{array}$ & $\begin{array}{l}\text { \#18: Example of strategies: Listen to everyone: make up my own mind (male, } S P \text { ); read } \\
\text { about it in magazines and other places (female, } S P \text { ); read articles, etc. on the internet } \\
\text { (male, TS); one can feel what is best for oneself and then ask for advice if one is doubtful } \\
\text { (female, TS). }\end{array}$ \\
\hline
\end{tabular}

Table 2. Note: Author's translation. Athlete's statements are not representative for all athletes. 


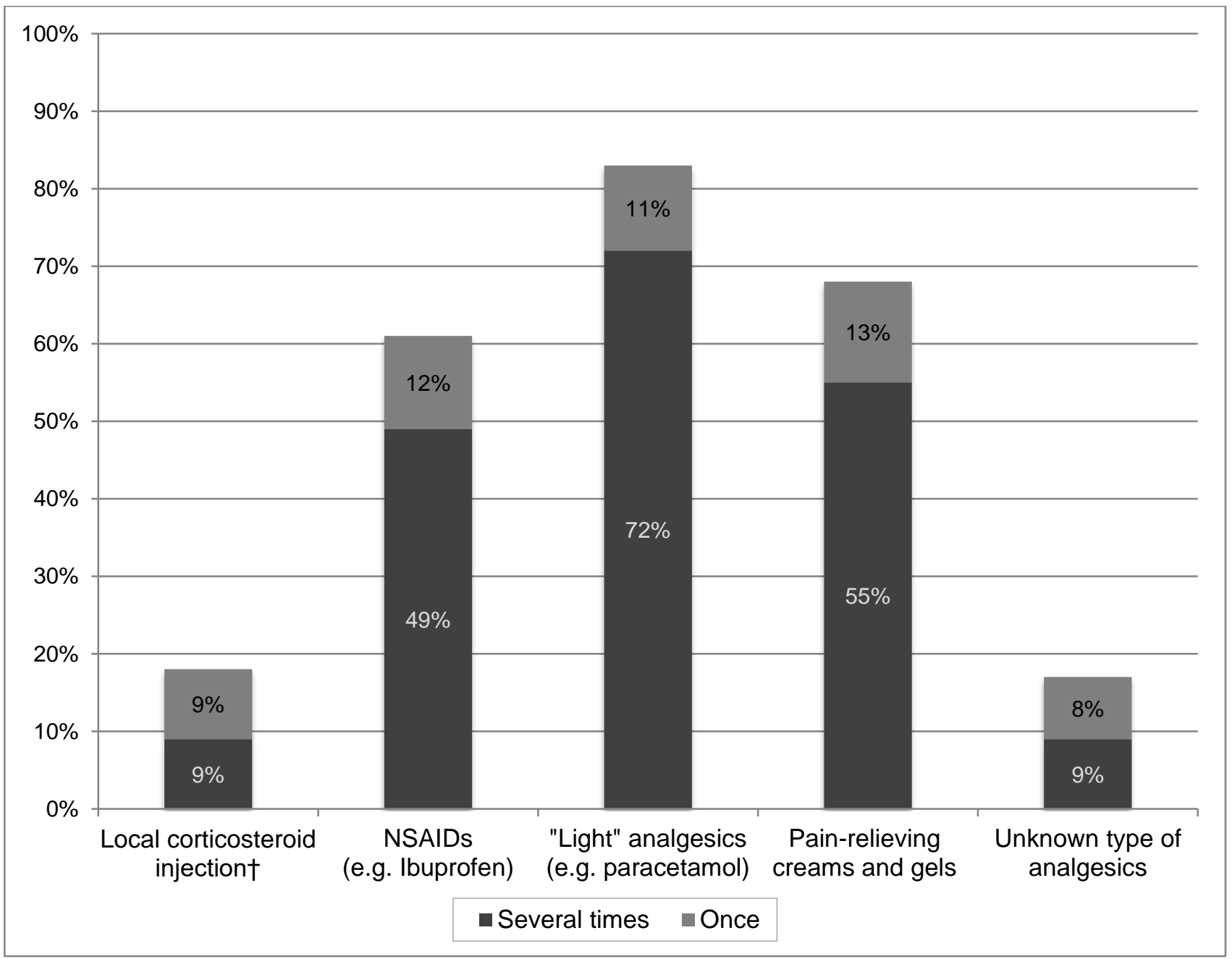

Figure 1: Athletes' experience with sport-related use of pain-relieving products ( $n=688 ; 8$ athletes did not know whether they had used painkillers). †Answer category in this item was: "one time" and "more than one time". 


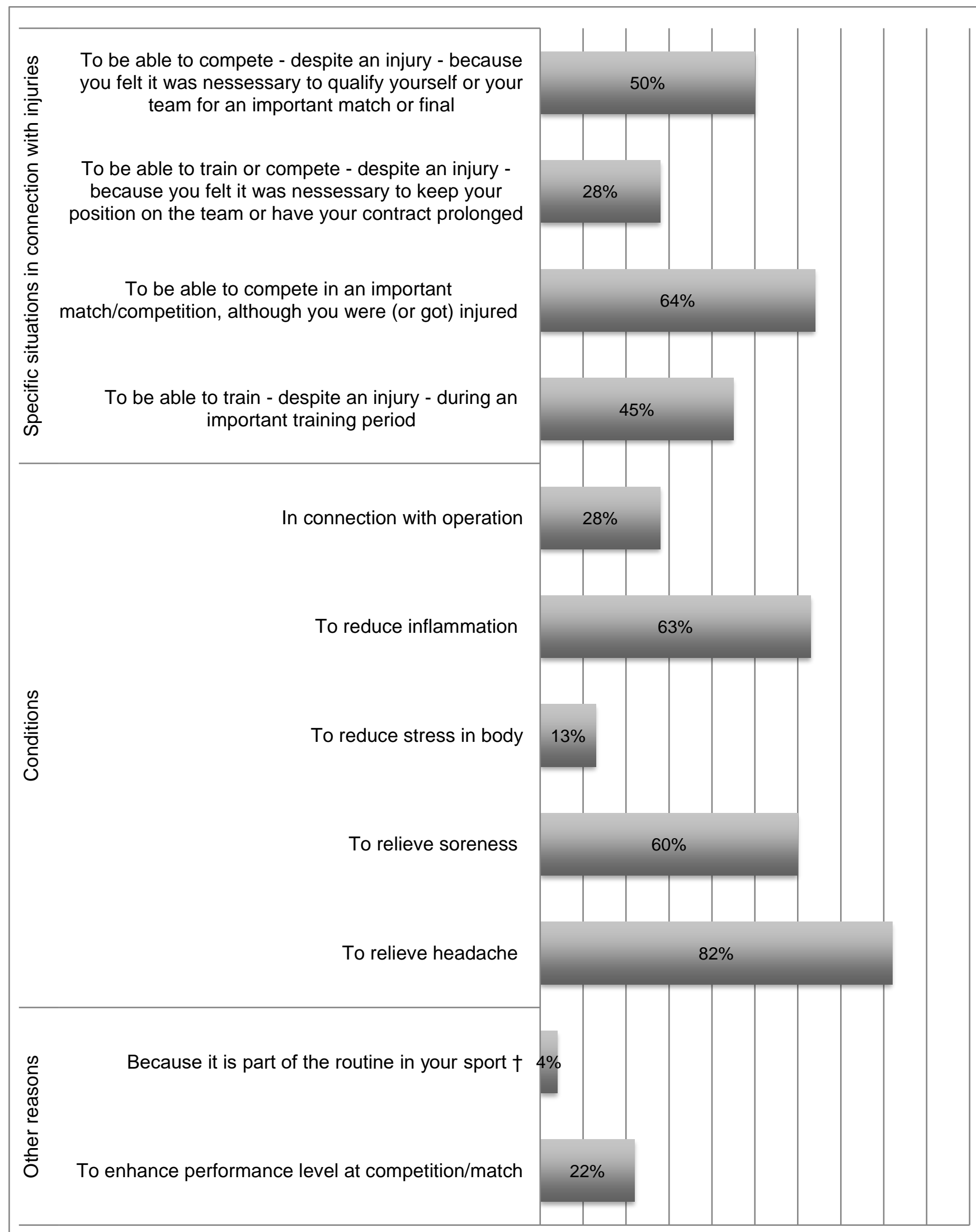

0\% $10 \% \quad 20 \% \quad 30 \% \quad 40 \% \quad 50 \% \quad 60 \% \quad 70 \% \quad 80 \% \quad 90 \% 100 \%$

Figure 2: Reasons and circumstances for use of painkillers among athletes with experience of the sportrelated use of painkillers ( $n=631)$. Note: the proportion of athletes who train or compete despite injury, but without pain-relieving medicines, may be significantly higher. $† 175$ of the athletes answered: "It is not like this in my sport". 


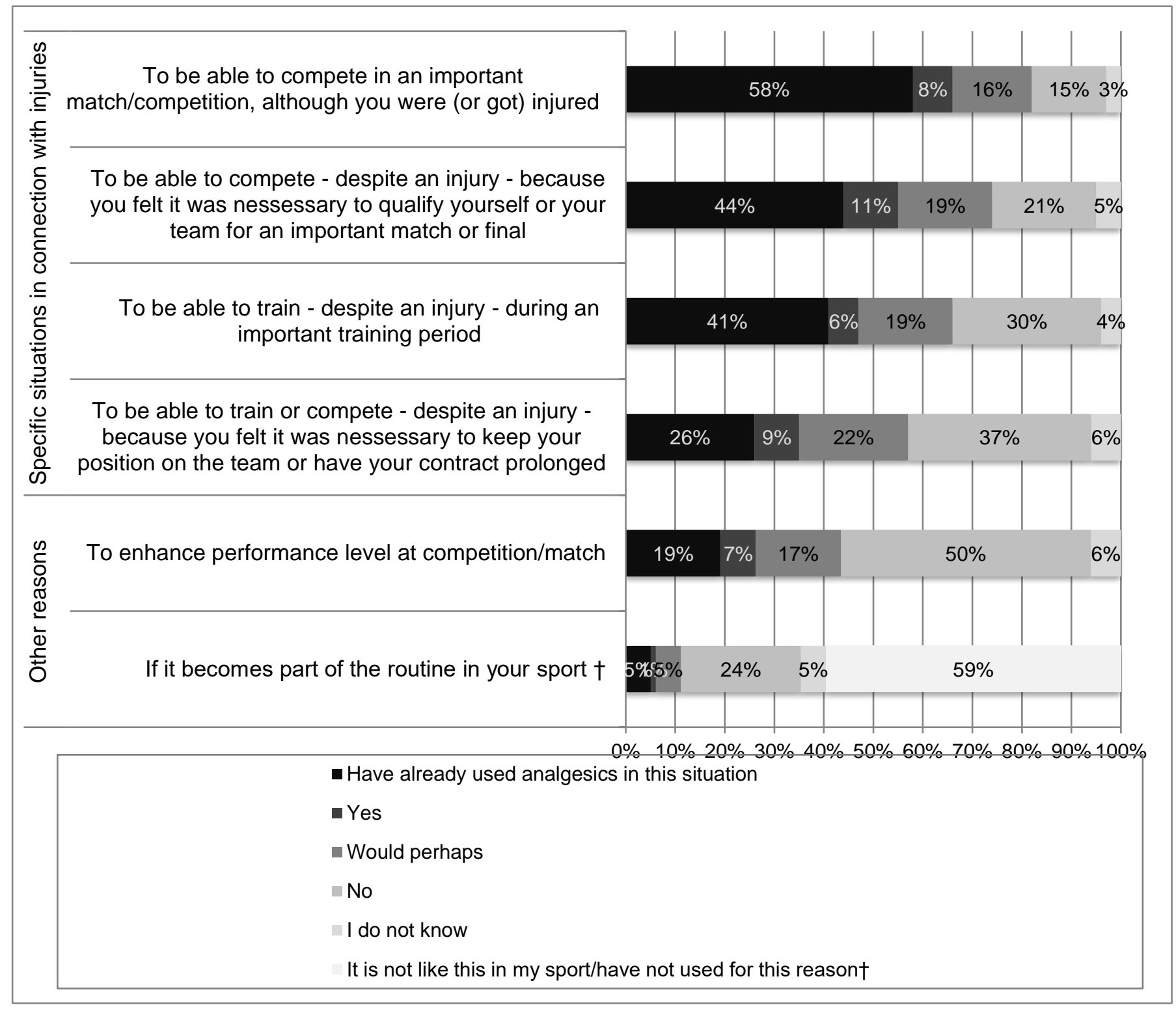

Figure 3: Use of - and willingness to use - analgesics in specific situations $(n=696)$. The answers include both those from Q2 and the willingness (or lack thereof) by athletes who had used painkillers, but not in the specific situation (Q3a), and those who had never used painkillers in a sporting context (Q3b). Note: differences in percentages between those who have used analgesics in Figures 2 and 3 are because Q2 only considers reasons among those who had used pain-relieving medicines $(n=631)$ and Figure 3 displays the overall number of athletes replying to the questions. 


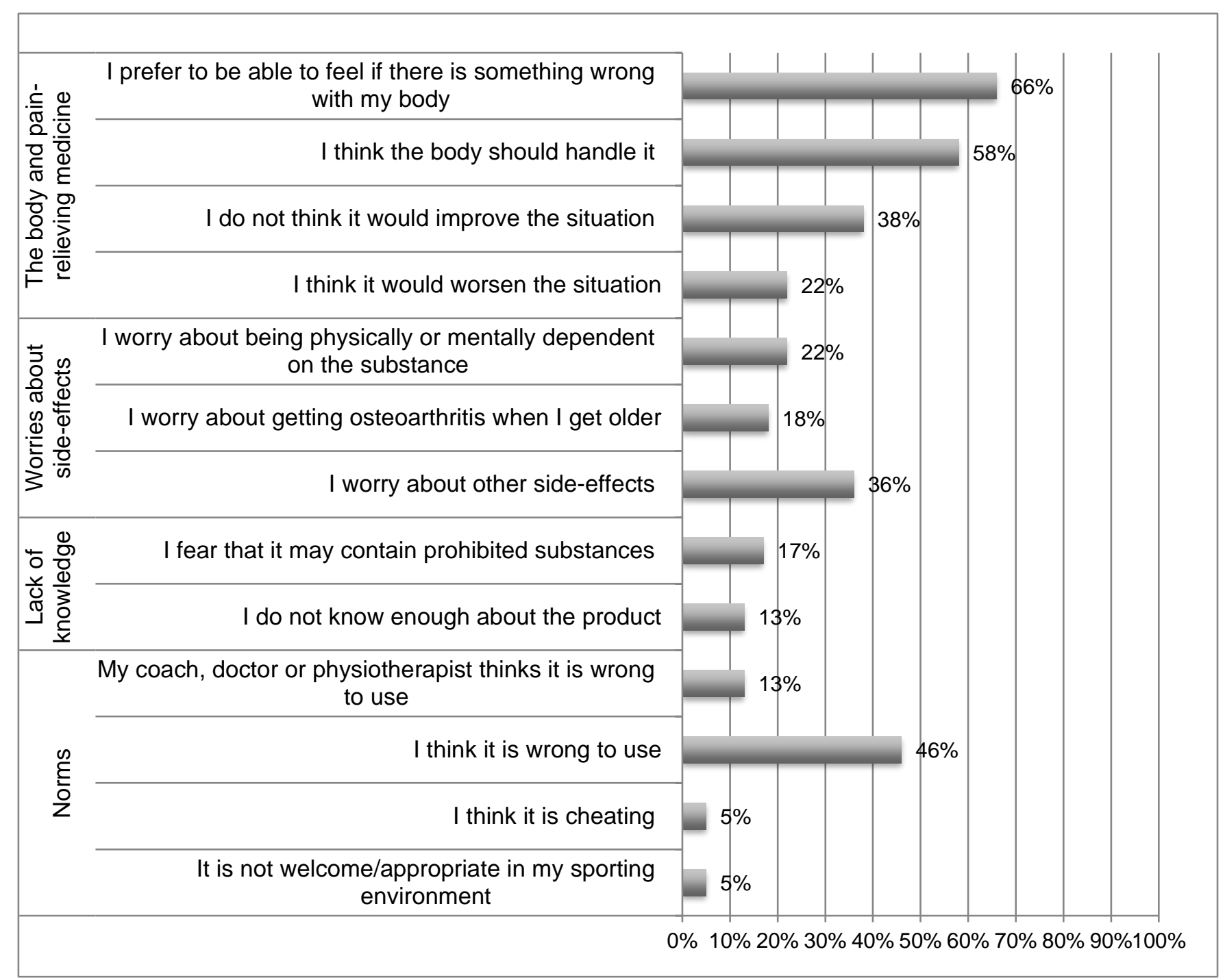

Figure 4: Reasons for (consciously) having decided to refrain from or minimise the sport-related use of pain-relieving medicines $(n=265)$. 


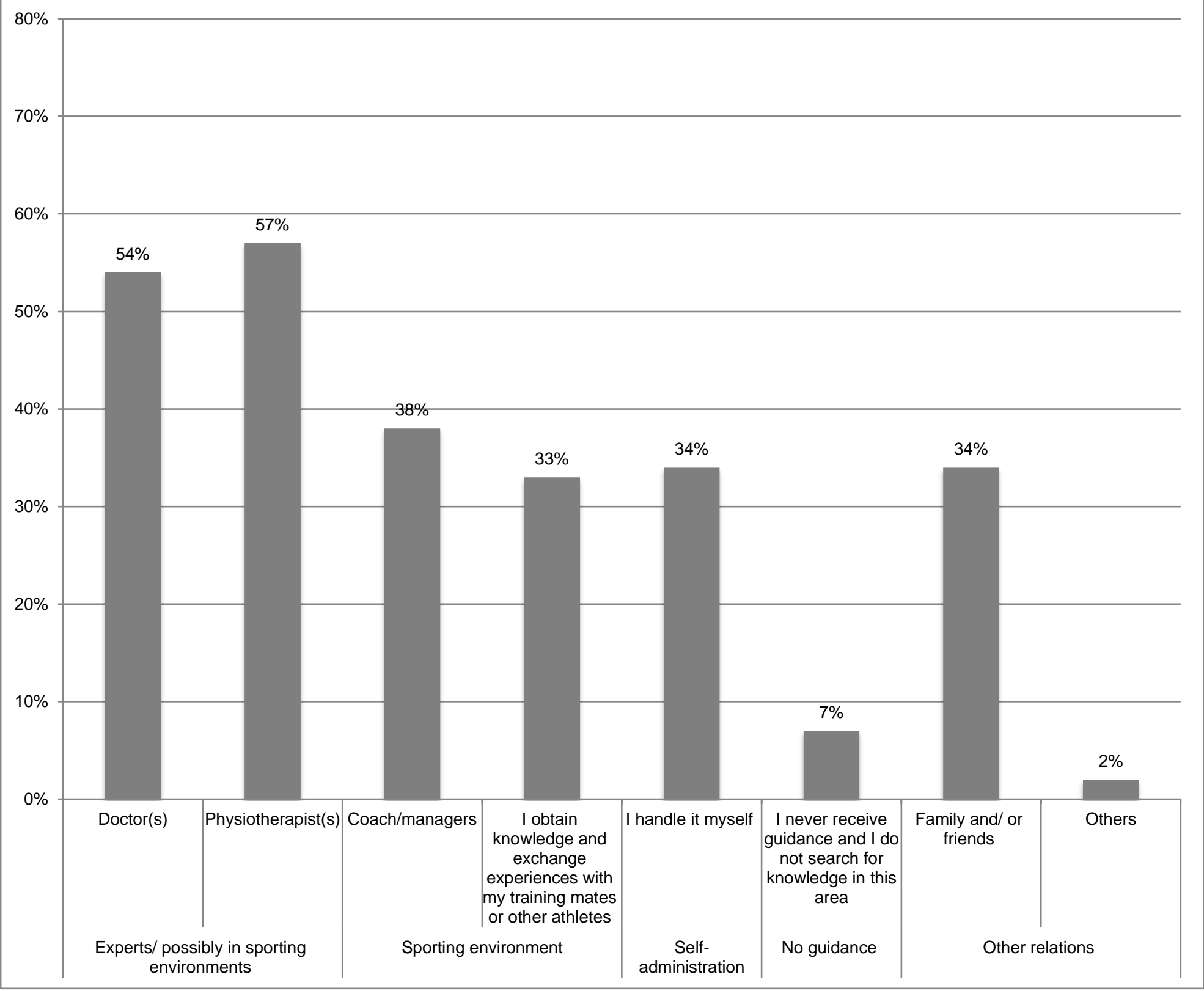

Figure 5: Sources of guidance on pain-relieving medicines ( $n=694)$. 